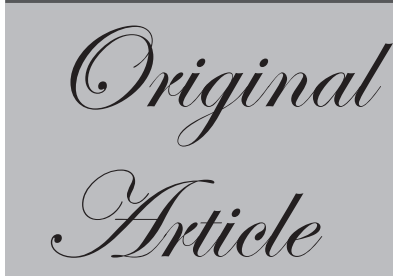

Department of Gastroenterology, Indira Gandhi Institute of Medical Sciences, Sheikhpura, Patna, Bihar

Corresponding Author:

Dr. Sanjeev Kumar Jha

Email:drsanjeevjha2010@gmail.com

\section{Efficacy of Nitazoxanide is Inferior to Metronidazole in Patients with Uncomplicated Amebic Liver Abscess: A Prospective Randomized Control Trial}

\author{
Sanjeev Kumar Jha, Uday Kumar, V M Dayal, \\ Amarendra Kumar
}

\section{ABSTRACT}

Background: In amebic liver abscess, aalthough metronidazole therapy is very effective in resolving infections; issues of incomplete clearance against intestinal ameba and Drug tolerability remain. Additionally, transmission of metronidazole-refractory amebiasis has been reported. In vitro studies reveal that nitazoaxanide are 1.5 times more active than metronidazole against amebiasis. Till now therapeutic efficacy of nitazoxanide has not been compared with metronidazole in patients with amebic liver abscess.

Material and Methods: This prospective randomized control study recruited 29 patients with uncomplicated amebic liver abscess. 15 patients received metronidazole ( $800 \mathrm{mg}$ tid. for 10 days) and 14 patients received nitazoxanide (500 mg bid. for 10 days). At 72 hour response to treatment was assessed by resolution of symptoms. In the absence of significant improvement in symptoms, therapeutic aspiration of liver abscess was done. Assessment of treatment response was done 48 hour after needle aspiration. If patients unresponsive to one treatment group at day 5, they were switched to other treatment group and treatment response was assessed after 48 hour. Results: At day three, $46.6 \%$ patients in metronidazole group developed significant clinical improvement whereas none of the patients in nitazoxanide group improved clinically. Therapeutic aspiration of liver abscess was done at day 3. Two days after therapeutic aspiration $93.3 \%$ patients in metronidazole group and $42.85 \%$ in nitazoxanide group improved clinically. At day 5, metronidazole $800 \mathrm{mg}$ three times per day was started in nitazoxanide unresponsive treatment group. All patients were improved clinically at day 7. Significant correlation of clinical improvement was found with metronidazole therapy, aspiration of liver abscess, and shorter hospital stay.

Conclusion: Nitazoxanide is inferior to metronidazole in treatment of patients with amebic liver abscess. Therapeutic aspiration hastens the rate of symptomatic improvement.

KEYWORDS: Amebic liver abscess, Metronidazole, Nitazoxanide, Aspiration. 


\section{Introduction}

Amebic liver abscess (ALA) is an inflammatory space -occupying lesion of the liver caused by Entamoeba histolytica. It is the most common extra intestinal manifestation of E. histolytica infection associated with significant morbidity and mortality if untreated.The incidence of ALA has been reported to vary between 3\% and $9 \%$ of all cases of intestinal amebiasis. ${ }^{1}$ Most patients present with an acute illness and duration of symptoms less than 2 weeks. The main presenting features are abdominal pain, fever, and anorexia. Ultrasound is very useful for diagnosis of amebic liver abscess. The classic appearance is a non-homogeneous, hypo echoic, round or oval mass with well defined border. Percutaneous diagnostic needle aspiration may be needed to differentiate amebic from pyogenic liver abscess. Serum antibodies to amebae are detected in $85-95 \%$ of all patients who present with invasive amebiasis or liver abscess. ${ }^{2}$ The absence of serum antibodies to E. histolytica after 1 week of symptoms is strong evidence against the diagnosis of invasive amoebiasis.

Most of the uncomplicated ALA can be treated successfully with amebicidal drug therapy alone. After completion of treatment with tissue amebicides, luminal amebicides should be administered for eradication of the asymptomatic colonization state. Failure to use luminal amebicides can lead to relapse of infection in approximately $10 \%$ of patients. $^{2}$ Metronidazole remains the drug of choice for amebic liver abscess. Metronidazole, 750 mg 3 times a day orally for 10 days, was reported to be curative in $90 \%$ of patients with amebic liver abscess. ${ }^{2}$ The drug is also available for intravenous administration for those patients who are unable to take oral medication. Resolution of symptoms is usually observed within 3 days, with the subsidence of toxaemia, abdominal pain, guarding, and tenderness in the right hypochondrium. ${ }^{2}$

Although metronidazole therapy is very effective in resolving infections, issues of incomplete clearance against intestinal amoeba remain. ${ }^{3}$ Additionally, transmission of metronidazole-refractory amebiasis has been reported. ${ }^{4}$ Drug tolerability is also a matter of concern. Usual adverse effects of metronidazole include nausea, vomiting, headache, epigastric discomfort and metallic taste. A disulfiram-like reaction may occur if alcohol is co-ingested. ${ }^{5}$ Based on above observation development of novel antiamebic drug is required.

Nitazoxanide, a 5-nitrothiazolyl derivative, is effective in the treatment of a broad range of parasitic infections. In vitro study revealed that nitazoaxanide and its metabolite tizoxanide are 1.5 times more active than metronidazole and other 5-nitroimidazole compounds against amebiasis. ${ }^{6}$ It also eliminates cysts or trophozoites from the stools in the post treatment period. ${ }^{7}$

Effect of nitazixanide in hepatic liver abscess was evaluated in prospective study from Egypt. That study showed all 17 patients with hepatic amebiasis responded to nitazoxanide therapy. ${ }^{8}$ Till now nitazoxanide has not been compared with metronidazole in patients with amebic liver abscess.

\section{Aim of the Study}

To compare the efficacy of nitazoxanide with metronidazole in patients with uncomplicated amebic liver abscess.

Primary end point was significant improvement in symptoms like pain abdomen and fever at 72 hour after initiation of therapy.

Secondary end points were:

1. Length in hospital stay.

2. Development of complications

3. Adverse effect of metronidazole or nitazoxanide

4. Reduction in abscess cavity size at month one

\section{Patients and Methods}

This was a prospective randomized control study. Study was approved by institutional ethics committee. Inclusion Criteria was as follows:

1. Clinical history and physical examination consistent with liver abscess.

2. Ultrasound abdomen showed space occupying lesion in liver, the sonographic feature which is consistent with abscess. Abscess was characterized by site (lobe), size (dimensions in $\mathrm{cm}$ ), number, distance from the liver capsule, vascular, and biliary structures. 
3. Positive amebic serology by ELISA

4. Size of abscess up to $6 \mathrm{~cm}$.

Following patients were excluded from study:

1. Ruptured liver abscess

2. Antibiotic treatment prior to randomization

3. Evidence of secondary bacterial infection

4. Altered sensorium at time of presentation

5. Allergy to either metronidazole or nitazoxanide

6. HIV Positive patient

7. Severe comorbities like cardiorespiratory disease, uncontrolled diabetes.

8. Associated chronic liver disease

9. Presence of Malignancy

10. Pregnancy

11. Refusal to give consent.

An informed written consent for the study participation was obtained from each patient. Microbiological examination of abscess fluid was done in all patients to exclude pyogenic abscess or superimposed bacterial infection. Ultrasound guided diagnostic aspiration of liver abscess was done. About $5 \mathrm{ml}$ pus was aspirated and sent for gram stain, culture (both aerobic and anaerobic) and sensitivity examination. After diagnosis, patients were randomized into either metronidazole group or nitazoxanide group. Dose of metronidazole was $800 \mathrm{mg}$ three times per day. Those patients who did not tolerate oral therapy were given intravenous therapy. Dose of intravenous metronidazole was $750 \mathrm{mg}$ three times per day. Dose of nitazoxanide was $500 \mathrm{mg}$ twice daily for 10 days. Laboratory investigations like complete blood count, liver function test, creatinine, electrolyte, blood sugar were measured serially. Chest X-ray was done when indicated, to rule out rupture of abscess into pleura. Other supportive treatment like albumin (if s. albumin is $<2.8$ ), intravenous fluid, nutritional supplement in malnourished patient was given as indicated.

Needle aspiration was done in presence of:

1. Left lobe abscess

2. Thin rim of liver tissue around the abscess $(<10 \mathrm{~mm})$

3. Failure of significant improvement of symptoms like pain abdomen and fever at 72 hour.
Aspiration was done using a long 18 gauge needle till the evacuation of all liquefied material.

Patients were said to be responding to treatment if there was significant improvement in symptoms like pain abdomen and fever at 72 hour after initiation of therapy. In the absence of significant improvement in symptoms, therapeutic aspiration of liver abscess was done. Assessment of treatment response was done 48 hour after needle aspiration. If patients unresponsive to one treatment group at day 5, they were switched to other treatment group and treatment response was reassessed after 48 hour.

Length in hospital stay, development of complications during hospital stay, adverse effect of drugs, and reduction in abscess cavity size were compared in both group.

\section{Statistical Analysis}

Quantitative datas were expressed as mean \pm standard deviation and analyzed using independent samples $\mathrm{T}$ test. Qualitative datas were expressed by percentage and analyzed by using Mann-Whitney U test. Logistic regression was carried out using an independent variable to analyze variable significantly associated with the final outcome. Statistical analysis was done using the SPSS 17.0 statistical package (IBM).

\section{Results}

This prospective study was conducted in between November 2014 and March 2017. Twenty nine consecutive patients of amebic liver abscess who met the inclusion criteria were included in this study. Baseline clinical and laboratory profile is listed in table $\mathbf{1}$. Average age of patient was $38 \pm 10.8$ year. All patients were male. Average duration of illness was $10.41 \pm 3.48$ days. $79.3 \%$ patients gave the history of toddy intake. Upper abdominal pain and fever were the most common symptoms, occurring in $96.7 .0 \%$ and $89.7 \%$ of the patients, respectively. Anorexia, chest pain, jaundice and diarrhea were seen in $67 \%, 58.6 \%, 19.8 \%$ and $9.9 \%$ respectively. Fever and tender hepatomegaly were the most common clinical signs elicited in $89 \%$ and $72 \%$ of patients respectively. 21,7 
and 1 patients had single abscess, two abscesses and three abscesses respectively. Average abscess diameter was $4.87 \pm 0.85 \mathrm{~cm} .22,4$ and 3 patients had isolated right lobe, isolated left lobe and bi-lobar involvement respectively. Gram stain and culture of aspirate material was negative in all patients.

After diagnosis 15 and 14 patients were randomized into metronidazole (800 $\mathrm{mg}$ three times per day) and nitazoxanide (500mg two times per day) treatment group respectively. Duration of drug therapy was 10 days. Both groups have similar clinical, laboratory and ultrasonological profile as mentioned in table 2.

Treatment response was assessed at day 3. 46.6\% patients in metronidazole group developed significant improvement in clinical symptoms whereas none of the patients in nitazoxanide group improved clinically. At day 3 , therapeutic aspiration was done in those patients who did not experience significant clinical improvement. 8 patients in metronidazole group and all 14 patients in nitazoxanide group required needle aspiration. $93.3 \%$ patients in metronidazole group and $42.85 \%$ in nitazoxanide group improved clinically at day 5. At day 5, metronidazole $800 \mathrm{mg}$ three times per day was started in those patients unresponsive to nitazoxanide
Table 1: Baseline clinical and laboratory profile of patients with liver abscess.

\begin{tabular}{l|l} 
Parameters & Results \\
\hline Age (year) $($ Mean \pm SD) & $38 \pm 10.9$ \\
\hline Sex (Male: Female) & $29: 0$ \\
\hline Pain Abdomen & $86(96.7 \%)$ \\
\hline Fever & $26(89.7 \%)$ \\
\hline Jaundice & $6(19.8 \%)$ \\
\hline Chest pain & $17(58.6 \%)$ \\
\hline Diarrhea & $3(9.9 \%)$ \\
\hline Anorexia & $20(67 \%)$ \\
\hline Hepatomegaly & $21(72.4 \%)$ \\
\hline History of toddy & $23(79.3 \%)$ \\
\hline Number of abscess $(1: 2: 3)$ & $21: 7: 1$ \\
\hline $\begin{array}{l}\text { Isolated Right lobe: Isolated left lobe: Both } \\
\text { lobe involvement }\end{array}$ & $22: 4: 3$ \\
\hline Abscess diameter $(\mathrm{cm})(\mathrm{Mean} \pm \mathrm{SD})$ & $4.71 \pm 0.85$ \\
\hline Duration of illness(Days) $(\mathrm{Mean} \pm \mathrm{SD})$ & $10.41 \pm 3.48$ \\
\hline Hemoglobin $($ gram/dl) $(\mathrm{Mean} \pm \mathrm{SD})$ & $9.7 \pm 1.6$ \\
\hline Leukocyte count $(\mathrm{cells} / \mathrm{cmm})(\mathrm{Mean} \pm \mathrm{SD})$ & $9912 \pm 3363$ \\
\hline Platelet $($ cells/cmm) $(\mathrm{Mean} \pm \mathrm{SD})$ & $1.53 \pm 0.62$ \\
\hline Bilirubin(mg/dl)(Mean $\pm \mathrm{SD})$ & $2.0 \pm 1.4$ \\
\hline SGPT $(\mathrm{IU} / \mathrm{ml})(\mathrm{Mean} \pm \mathrm{SD})$ & $62 \pm 33$ \\
\hline S.Alkaline phosphatase $(\times \mathrm{UNL})(\mathrm{Mean} \pm \mathrm{SD})$ & $2.42 \pm 1.04$ \\
\hline S. Albumin $(\mathrm{gm} / \mathrm{dl})(\mathrm{Mean} \pm \mathrm{SD})$ & $3.31 \pm 0.59$ \\
\hline &
\end{tabular}

Table 2: Baseline profile: comparison between metronidazole group and Nitazoxanide group.

\begin{tabular}{|c|c|c|c|}
\hline Parameters & Metronidazole $(\mathrm{n}=15)$ & Nitazoxanide $(n=14)$ & P Value \\
\hline Age(Years) $($ Mean \pm SD) & $37.06 \pm 10.08$ & $40.07 \pm 11.88$ & 0.46 \\
\hline Pain Abdomen & $100 \%$ & $93 \%$ & 0.74 \\
\hline Fever & $100 \%$ & $85.71 \%$ & 0.74 \\
\hline Chest Pain & $66 \%$ & $50 \%$ & 0.57 \\
\hline Jaundice & $26.7 \%$ & $14.3 \%$ & 0.59 \\
\hline Hepatomegaly & $73.3 \%$ & $71.4 \%$ & 0.94 \\
\hline History of toddy intake & $80 \%$ & $78.6 \%$ & 0.94 \\
\hline Duration of illness(Days) (Mean \pm SD) & $9.66 \pm 3.1$ & $11.21 \pm 3.78$ & 0.24 \\
\hline Hemoglobin(Gram/dl) $($ Mean \pm SD $)$ & $9.99 \pm 1.8$ & $9.40 \pm 1.36$ & 0.33 \\
\hline Leukocyte (per cmm) (Mean \pm SD) & $10556 \pm 3972$ & $9221 \pm 2525$ & 0.29 \\
\hline Blirubin(mg/dl) (Mean \pm SD) & $2 \pm 1.3$ & $2.0 \pm 1.5$ & 0.99 \\
\hline $\operatorname{Albumin}(\mathrm{gm} / \mathrm{dl})(\mathrm{Mean} \pm \mathrm{SD})$ & $3.2 \pm 0.61$ & $3.4 \pm 0.50$ & 0.39 \\
\hline $\mathrm{SGPT}(\mathrm{IU} / \mathrm{ml})($ Mean $\pm \mathrm{SD})$ & $67 \pm 33$ & $57 \pm 33$ & 0.43 \\
\hline Alkaline phosphatase $(\times \mathrm{UNL})($ Mean $\pm \mathrm{SD})$ & $2.5 \pm 1.17$ & $2.3 \pm 0.91$ & 0.55 \\
\hline Number of abscess(Mean \pm SD) & $1.33 \pm 0.48$ & $1.28 \pm 0.61$ & 0.81 \\
\hline Diameter of abscess $(\mathrm{cm})($ Mean \pm SD) & $4.7 \pm 0.85$ & $4.6 \pm 0.88$ & 0.64 \\
\hline Right lobe: Left lobe & $13: 3$ & $12: 4$ & \\
\hline
\end{tabular}


Table 3: Comparison of treatment outcome between Metronidazole and Nitazoxanide group.

\begin{tabular}{l|l|l|l}
\hline Patient's Outcome & $\begin{array}{l}\text { Metronidazole } \\
\text { group }(\mathbf{n}=\mathbf{1 5})\end{array}$ & $\begin{array}{l}\text { Nitazoxanide } \\
\text { group }(\mathbf{n = 1 4})\end{array}$ & P Value \\
\hline Symptomatic improvement at day 3 & $7(46.6 \%)$ & 0 & 0.004 \\
\hline Aspiration needed & $8(53.3 \%)$ & $14(100 \%)$ & 0.033 \\
\hline Symptomatic improvement after aspiration at day 5 & $14(93.3 \%)$ & $6(42.85 \%)$ & 0.004 \\
\hline $\begin{array}{l}\text { Symptomatic improvement at day 7 after switched } \\
\text { from nitazoxanide to metronidazole group }\end{array}$ & $15(100 \%)$ & $14(100 \%)$ & 1 \\
\hline Mean hospital stay (Days) & $6.93 \pm 2.05$ & $8.57 \pm 1.50$ & 0.021 \\
\hline Decrease in abscess size at 1 month by $>50 \%$ & 9 patients & 10 patients & 0.62 \\
\hline
\end{tabular}

Table 4: Comparison of variables between patients group that responded to drug therapy only versus that needed additional therapeutic liver abscess aspiration.

\begin{tabular}{|c|c|c|c|}
\hline Parameters & $\begin{array}{l}\text { Aspiration needed } \\
(\mathrm{n}=22)\end{array}$ & $\begin{array}{l}\text { Aspiration not needed } \\
(\mathrm{n}=7)\end{array}$ & P Value \\
\hline Age (Years) (Mean +SD) & $40.40 \pm 11.35$ & $32.57 \pm 6.99$ & 0.09 \\
\hline Pain Abdomen & $95.5 \%$ & $100 \%$ & 0.57 \\
\hline Fever & $86.4 \%$ & $100 \%$ & 0.31 \\
\hline Chest Pain & $59.1 \%$ & $57.1 \%$ & 0.92 \\
\hline Hepatomegaly & $77.3 \%$ & $57.1 \%$ & 0.30 \\
\hline History of toddy intake & $77.3 \%$ & $85.7 \%$ & 0.63 \\
\hline Duration of illness(Days) (Mean \pm SD) & $10.54 \pm 3.69$ & $10.00 \pm 2.94$ & 0.72 \\
\hline Hemoglobin $($ Gram/dl) $($ Mean \pm SD $)$ & $9.31 \pm 1.38$ & $10.94 \pm 1.74$ & 0.01 \\
\hline Leukocyte (per cmm) (Mean \pm SD) & $10668 \pm 3284$ & $7535 \pm 2515$ & 0.02 \\
\hline Blirubin(mg/dl) (Mean \pm SD) & $2.30 \pm 1.53$ & $1.07 \pm 0.38$ & 0.04 \\
\hline $\operatorname{Albumin}(\mathrm{gm} / \mathrm{dl})($ Mean \pm SD) & $3.18 \pm 0.62$ & $3.7 \pm 0.28$ & 0.04 \\
\hline $\mathrm{SGPT}(\mathrm{IU} / \mathrm{ml})(\mathrm{Mean} \pm \mathrm{SD})$ & $66.86 \pm 36.59$ & $47.57 \pm 11.07$ & 0.18 \\
\hline Alkaline phosphatase $(\times \mathrm{UNL})($ Mean $\pm \mathrm{SD})$ & $2.65 \pm 1.03$ & $1.70 \pm 0.74$ & 0.03 \\
\hline Diameter of abscess $(\mathrm{cm})($ Mean \pm SD $)$ & $4.94 \pm 0.85$ & $3.98 \pm 0.24$ & 0.007 \\
\hline Hospital stay(Days) (Mean \pm SD) & $8.59 \pm 1.25$ & $5.00 \pm 1.00$ & 0.001 \\
\hline Decrease in abscess size by $>50 \%$ at month 1 & $63.6 \%$ & $71.4 \%$ & 0.78 \\
\hline
\end{tabular}

therapy. All patients in metronidazole as well as in nitazoxanide treatment group improved clinically, significantly. Hospital stay in metronidazole treatment group (6.93 \pm 2.05 days) was shorter than nitazoxanide treatment group ( $8.57 \pm 1.50$ days). No major drug related adverse effect developed during treatment. Metallic taste of mouth seen in 6 patients, anorexia in 7 patients and nausea in 3 patients during treatment with metronidazole. No major nitazoxanide induced adverse effect noted.

Ultrasound abdomen was done after 1 month to assess the abscess cavity size. 9 patients in metronidazole treatment group and 10 patients in nitazoxanide treatment group showed decrease in abscess cavity size by more than $50 \%$. Clinical, laboratory and treatment response profile were compared between groups of patients, whether therapeutic liver aspiration was needed or not. We found that likelihood of aspiration is significantly associated with low hemoglobin level, leukocytosis, high bilirubin level, hypoalbuminemia, increased alkaline phosphatase level and larger abscess diameter. We have 
done correlation analysis by using logistic regression method, and showed significant correlation of clinical improvement with metronidazole therapy, aspiration of liver abscess, and shorter hospital stay.

\section{Discussion}

In amebic liver abscess, metronidazole is considered to be very effective in resolving infections but drug tolerability by patients remain an important concern. Additionally, transmission of metronidazole-refractory amebiasis has been reported. It also has no effect on luminal cysts. Based on above observation development of novel antiamebic therapies is required.

Nitazoxanide, a 2 acetyloxy-N (5-nitro-2thiazolyl) benzamide is well absorbed from the gut. It interferes with pyruvate ferredoxin oxidoreductase (PFOR) enzyme dependent electron transfer reaction which is important for anaerobic glucose energy metabolism. This results in cell swelling, membrane damage and vacuole injury of the trophozoites, resulting in dysfunction of the parasite. ${ }^{9}$ In humans, nitazoxanide and its major circulating metabolites tizoxanide are heavily concentrated in the intestinal tract. Approximately 33\% of an oral dose is excreted in urine and $67 \%$ in faeces. ${ }^{10}$ In vitro study revealed that nitazoaxanide is 1.5 times more active than metronidazole against amebiasis. It also eliminates cysts or trophozoites from the stools in the post treatment period.

We have found only one study on effect of nitazoxanide in patients with hepatic amebiasis. ${ }^{8}$ In that study, seventeen adults hospitalized with hepatic amebiasis were treated with 500mg nitazoxanide twice daily for 10 days. All patients with hepatic amebiasis responded to nitazoxanide therapy. But no prospective study has done so far that compare nitazoxanide with metronidazole in patients with amebic liver abscess.

In our study treatment response was assessed at day 3 after drug institution. $46.6 \%$ patients in metronidazole group developed significant improvement in clinical symptom whereas none of the patients in nitazoxanide group improved clinically. Other studies showed that metronidazole is effective in $80-95 \%$ of cases. ${ }^{2,11} \mathrm{~A}$ recent retrospective study showed that antibiotics alone are effective in about $45.6 \%$ cases. $^{12}$ Relatively low response of metronidazole in our study was mainly because of persistence of abdominal pain and tenderness at day 3. Persistence of pain or discomfort might be due to pressure effects of abscess on the Glisson's capsule. After therapeutic aspiration at day three, 93.3\% patients in metronidazole group and $42.85 \%$ in nitazoxanide group improved clinically at day 5 . Drugs alone are not effective in clearing the necrotic material mechanically; hence do not rapidly reduce the pain. Aspiration causes reduced pressure on surrounding parenchyma and therefore leads to rapid reduction in pain and discomfort. The routine use of aspiration remains debatable and has generated considerable controversy amongst clinicians. In the case of uncomplicated ALA, one initial study showed metronidazole is optimally effective and routine aspiration is not required. ${ }^{13}$

Other study suggested that needle aspiration enhances clinical recovery, accelerates resolution and prevents complications..$^{14}$ It is important to drain left lobe ALA as there is danger of rupture in the pericardial sac. Ghosh et al showed that needle aspiration along with metronidazole hastens clinical improvement especially in large $(>5 \mathrm{~cm})$ cavities in patients with ALA. Aspiration is safe and no major complications occurred. ${ }^{15}$

A recent Cochrane review concluded that therapeutic aspiration in addition to metronidazole to hasten clinical or radiologic resolution of uncomplicated ALA, cannot be supported or refuted by the present evidence.The same review pointed out that the number of days to resolution of pain in the needle aspiration plus metronidazole group were less as compared to metronidazole group only. ${ }^{16}$

Our study found low efficacy of nitazoxanide in liver abscess. Even after therapeutic aspiration of liver abscess, only $42.85 \%$ showed significant symptomatic improvement. A study observed that oral administration of $500 \mathrm{mg}$ of nitazoxanide bid. for 7 days in healthy volunteers is not associated with any significant accumulation of nitazoxanide metabolite whereas $1000 \mathrm{mg}$ bid is associated with significant accumulation of nitazoxanide metabolite. ${ }^{17}$ Lower efficacy of nitazoxanide may possibly be related to its suboptimal concentration in abscess cavity. It may be possible that the dose of nitazoxanide is 
suboptimal to treat amebic liver abscess.

Our study has some limitations also. Sample size of our study is small. Other limitation is that in metronidazole group we have used both oral and intravenous administration but nitazoxanide drug has only oral formulation available. The difference in route of administration might causes difference in efficacy between two treatment limbs. Nevertheless our study is the first prospective study that compares nitazoxanide with metronidazole in patients with amebic liver abscess. This study clearly showed inferior efficacy of nitazoxanide as compared to metronidazole in patients with amebic liver abscess.

\section{Conclusion}

Nitazoxanide is inferior to metronidazole in treatment of patients with amebic liver abscess. Therapeutic aspiration of liver abscess hastens the rate of symptomatic improvement.

\section{References}

1. Peters RS, Gitlin N, Libke RD. Amoebic liver diseases. Ann Rev Med.1982; 32: 161-74.

2. M P Sharma, Vineet Ahuja. Amebic Liver Abscess. JIACM. 2003; 4(2): 107-11.

3. Samarawickrema NA, Brown DM, Upcroft JA, Thammapalerd N, Upcroft P. Involvement of superoxide dismutase and pyruvate:ferredoxin oxidoreductase in mechanisms of metronidazole resistance in Entameba histolytica. J Antimicrobial Chemotherapy. 1997; 40: 833840

4. Fujishima T, Nishise S, Ichihara M, Kobayashi S, Takeuchi T. Difficulties in the treatment of intestinal amoebiasis in mentally disabled individuals at a Rehabilitation Institution for the Intellectually Impaired in Japan. Chemotherapy.2010; 56:348-352

5. Current Medical Diagnosis and Treatment. 2015:1494

6. Cedillo Rivera R, Chavez B, Gonzalez Robles A, Tapia A, Yepez Mulia L. In vitro effect of Nitazoxanide against Entameba histolytica, Giardia intestinalis and Trichomonas vaginalis trophozoites. J Eukaryot Microbiol.2002; 49(3):201-8

7. Baily JM, Erramouspe J. Nitazoxanide treatment for giardiasis and cryptosporidiosis in children. Ann Pharmcother. 2004; 38: 634-40.

8. Rossignol JF, Kabil SM, EL Gohary Y, Younis AM. Nitazoxanide in the treatment of amebiasis. Trans R Soc Trop Med Hyg.2007; 101(10):1025-31.

9. Sapna Gupta, Vishal R. Tandon, Sunil Dutt Sharma, Ritu Gupta, Ravinder K. Gupta. Nitazoxanide: Broad Spectrum Anti-Protozoal. JK Science. 2006 Vol. 8 No. 1, JanuaryMarch.

10. Broekhuysen J, Stockis A, Lins RL, De Graeve J, Rossignol JF.Nitazoxanide: Pharmacokinetics and metabolism in man. Int J Clin Pharmacol Ther.2000; 38(8):387-94.

11. Kale S, Nanavati AJ, Borle N, Nagral S. Outcomes of a conservative approach to management in amoebic liver abscess. J Post Grad Med. 2017; 63(1):16-20.

12. Satyarth Chaudhary, Mohd.Talha Noor, Sunil Jain, Ravindra Kumar, Bhagwan Singh Thakur. Amebic liver abscess: a report from central India. Tropical Doctor.2016; 46(1) 12-15

13. M P Sharma, R R Rai, S K Acharya, J C Samant Ray, B $\mathrm{N}$ Tandon. Needle aspiration of amoebic liver abscess. BMJ.1989; 299:1308-09

14. Ananthakrishnan Ramani, Rama Ramani, M.S. Kumar, B.N. Lakhkar and G.N. Kundaje. Ultrasound-guided needle aspiration of amoebic liver abscess. Post grad Med J (1993) 69, $381-383$

15. Jayant Kumar Ghosh, Sundeep Kumar Goyal, Manas Kumar Behera, Manish Kumar Tripathi, Vinod Kumar Dixit, Ashok Kumar Jain, Ramchandra Shukla. Efficacy of aspiration in amoebic liver abscess. Tropical Gastroenterology 2015; 36(4):251-255

16. Chavez-Tapia NC, Hernandez-Calleros J, Tellez-Avila FI, Torre A, Uribe M. Image-guided percutaneous procedure plus metronidazole versus metronidazole alone for uncomplicated amoebic liver abscess. Cochrane Database of Systematic Reviews 2009, Issue1

17. Stockis A, De Bruyn S, Gengler C, Rosillon D. Nitazoxanide pharmacokinetics and tolerability in man during 7 days dosing with $0.5 \mathrm{~g}$ and $1 \mathrm{~g}$ b.i.d. Int J Clin Pharmacol Ther. 2002; 40(5):221-7. 